\title{
Letter
}

\section{The Loch Ness monster and La Palma giant lizard Gallotia auaritae: are they really extant?}

A photograph taken of a lizard on La Palma, Canary Islands, in July 2007 and published in the Spanish national newspaper El País has been considered evidence of another species of so-called giant lizard from the Canary Islands. This information was echoed by Richard P. Brown in the Conservation News of Oryx (42, 171-172). Although some photographs can lead to the discovery of a new species or prove the existence of supposedly extinct ones, others, such as those of the Loch Ness monster in Scotland, have only produced a topic for animated conversation, along with varied explanations, popular beliefs or legends. The lizard's photograph was also published in regional newspapers and eventually another photograph was published in the Bulletin of the Spanish Herpetological Society (Mínguez et al., 2007; Boletín de la Asociación Herpetológica Española, 18, 11-13). According to the authors the lizard corresponds to the extinct Gallotia auaritae, a taxon previously described as a subspecies of Gallotia simonyi based on subfossil remains.

However, the photograph does not provide good scientific evidence for the survival of a giant lizard on La Palma, and the lizard could actually be the abundant native species Gallotia galloti. The authors excluded this species from consideration because of its size and colouration. They mentioned that the snout-vent length (SVL) of G. galloti palmae, the endemic subspecies of La Palma, never exceeds $120 \mathrm{~mm}$. But on Tenerife the SVL of G. galloti clearly surpasses this length, and on Roque de Fuera de Anaga some individuals reach at least $145 \mathrm{~mm}$ SVL. Moreover at some localities on La Palma it is possible to observe large specimens of G. galloti palmae similar in size to the lizards found on Tenerife. The picture of the supposed giant lizard was taken at a distance of c. $10 \mathrm{~m}$ and the total length (301$312 \mathrm{~mm})$ and SVL (157-167 mm) were estimated a few months later by comparison with the surrounding plants and stones. The way these measurements were taken is obviously not very reliable and therefore it is uncertain if the lizard was a large G. galloti or a small G. auaritae.
With respect to the colouration, the authors indicate that the photograph is not that of G. g. palmae because the dorsum is very dark and lacking any markings and the gular region is not blue. However, the colouration in G. galloti is very variable, and lizards from the north of Tenerife are similar to G. g. palmae. The lizards from the south of Tenerife look different and, curiously, their general colouration is very similar to that described for the supposed giant lizard from La Palma. On La Palma, where variation has been less studied, lizards with similar colouration to those found in the southern part of Tenerife but clearly identified as G. g. palmae have been observed. In addition, a zoom of the published photographs show some blue pixels in the gular region and above the fore limbs.

This weak photographic evidence was published after the authors revisited the area without finding any further trace of the lizard. It is clear that if a true giant lizard is discovered on La Palma the population must be small and on the verge of extinction, urgently in need of protection measures. However the finding has not been officially communicated to the local environmental authorities of La Palma. Surprisingly, IUCN has given credit to this supposed discovery, categorizing G. auaritae as Critically Endangered in the 2008 IUCN Red List of Threatened Species (http://www.iucnredlist.org). Although it is possible that a giant lizard still survives on some cliff areas of La Palma, as do Gallotia intermedia on Tenerife and Gallotia gomerana on La Gomera, the published information is not convincing. I strongly recommend that IUCN remove this ghost species from the Red List. Evidence for its existence is no stronger than that for the Loch Ness monster, the Yeti of the Himalayas, the Mokele-mbembe of Central Africa or Bigfoot of North America.

\section{AURELIO MARTíN}

Departamento Biología Animal (Zoología)

Universidad de La Laguna, 38206 La Laguna-Tenerife

Canary Islands, Spain

E-mail aumartin@ull.es 